\title{
No princípio era poeira: cruzamentos da extensáo e da pesquisa cênica em A Vida de Galileu, de Bertold Brecht
}

In the beginning it was dust: crosses of extension and scenic research in "Life of Galileo" by Bertold Brecht

\section{RESUMO}

Este artigo resulta de um processo de extensão/pesquisa, desenvolvido no curso de Teatro da na Universidade Federal de Uberlândia (UFU), e que, a partir dos estudos dos possíveis entrelaçamentos entre arte e ciência, propusemos investigaçóes cênicas e apresentações teatrais da clássica peça $A$ Vida de Galileu, do alemão Bertold Brecht. $\mathrm{O}$ processo/espetáculo agregou atores universitários e artistas egressos da comunidade. Esse encontro propiciou tencionar as fronteiras entre arte e ciência, permitindo compreender que a questão da inovação e da criatividade aproximam ambas. Principalmente, permitiu a convivência cênica dos participantes e a oportunidade de ir ao teatro, seja de jovens universitários seja dos moradores dos locais em que o espetáculo foi apresentado.

Palavras-chave: Extensão universitária. Artes cênicas. Ciência.

\section{ABSTRACT}

This article is a result of an extension process/research developed at the Theater Course of the Federal University of Uberlândia (UFU), in which, from the studies about the possible interweaving between art and science, we proposed theatrical investigations and theatrical presentations of the classic play Life of Galileo, by the German author Bertold Brecht. The process/performance brought together university actors and artists from the community. This meeting made possible to us to measure the boundaries between art and science, allowing us to understand that the matter of innovation and creativity brings them both much closer. Mainly, it allowed the scenic interaction of the participants and it created an opportunity to go to the theater, whether it was an oportunity for the university students or the community members from the places where the play was performed.

Keywords: Academic extension. Scenic arts. Science.

O espetáculo teatral Galileu Galilei resultou de um longo e intenso projeto de pesquisa e extensão desenvolvido na Universidade de
Luiz Humberto Martins Arantes

Pós-doutorando na Universidade Autonoma de Barcelona, Espanha; Universidade do Estado de Santa

Catarina, Brasil; pesquisador, diretor e professor associado IV no Instituto de Artes da Universidade Federal de Uberlândia, Minas Gerais, Brasil (lharantes@ufu.br) 
Uberlândia (UFU) ${ }^{1}$ com apoio financeiro da própria universidade e da FAPEMIG (Fundação de Amparo à Pesquisa do Estado de Minas Gerais). O ponto de partida para a montagem cênica $^{2}$ foi a ideia de popularização da ciência e o estudo do texto teatral Vida de Galileu, do dramaturgo alemão Bertolt Brecht (1898-1956), escrito no final da década de 1930 .

A ousadia vinha do fato de ser um texto poucas vezes montado no Brasil e da necessidade de mergulho em questóes sobre ciência, seus conceitos e as descobertas astronômicas de Galileu. Em termos práticos, tratava-se também de um texto repleto de personagens complexos.

Montar Brecht é um desafio e um ideal que, normalmente, surge de motivaçóes apaixonadas. Porque Brecht concebeu um teatro, um material teórico, textos dramáticos, e tudo isso dentro de uma temática específica, que foi a da guerra, e dentro de um contexto específico, aquele entre as duas grandes guerras na Alemanha, além do que ele dominava todo um referencial específico; o contexto em que ele estava inserido era diferente do contexto brasileiro. (CELSO NETO, 2006).

Em um primeiro momento, entendemos que o mais importante era agregar pessoas que estivessem realmente interessadas em contar aquela história, assim, a quantidade significativa de personagens em relação ao número de atores e o longo texto náo seriam problemas insolúveis diante da vontade de estarmos em cena contando aquela narrativa brechtiana.

No início do processo, reuniam-nos para fazer estudo de mesa, que consistia em leituras dramáticas e leituras "neutras"3" do texto de Brecht, na tentativa de compreender os personagens e as informaçóes contidas nas entrelinhas. Estudávamos, em paralelo, a vida de Galileu desde seu nascimento e formaçáo, como ainda as suas grandes descobertas e embates. Inclusive, identificamos algumas coincidências entre as vidas de Galileu e Brecht.

Inicialmente agregamos um coletivo de nove pessoas, mas com o passar do tempo nos tornamos sete. Bastante compreensível, pois o processo teatral comumente acaba por se tornar uma seleção natural, ficando somente quem de fato se interessava pelo projeto e/ou quem se dispunha a ensaiar nos horários definidos. Ficou também quem
${ }^{1}$ Desenvolvido a partir do ano de 2010 , o projeto teve a minha coordenação junto à FAPEMIG.

Foram incorporados como participantes atores: alunos, ex-alunos e convidados da comunidade que se interessaram pela ideia, muitos deles motivados pela novidade que era, naquele momento, realizar uma montagem tão desafiadora.

2 Elenco: Ana Flávia Felice, Breno Maia, Cássio Machado, Kalassa Lemos, Lilia Pitta, Narlo Rodrigues,

Umberto Tavares, Valéria Gianechini. Direçâo Cênica: Yaska Antunes. Produção e Coordenação: Luiz Humberto Arantes.

3 Entende-se por essa expressão o exercício de uma leitura de texto teatral sem a definição prévia de personagens e sem a necessidade de impostação da voz do ator. 
acreditava no diálogo entre o conhecimento artístico acadêmico e os saberes da comunidade externa à universidade.

Na sequência, compreendemos que não bastaria somente o estudo da obra brechtiana, tornou-se necessário também aprofundar a instigante relação entre arte e ciência. Na longa história da arte teatral têm sido recorrentes enredos que remetem ao processamento de temas científicos. A palavra "inovação" pode ter um uso terminológico e conceitual recente, mas, tanto "teatro" quanto "ciência" trabalham diretamente com a questão da criação e da experimentação desde muito tempo.

As peças que tematizam a questão da ciência em seus enredos, em alguns casos, iluminam biografias de importantes cientistas, suas descobertas e histórias de vida, ou narram histórias de grandes descobertas/invençóes, mas quase todas ressaltam a rotina, o passo a passo de um caminho que levou anos para se realizar.

Imagem 1 - Cena de Galileu Galilei. Em cena, da esquerda para a direita, os atorxs Breno Maia, Narlo Santos, Valéria Gianechini, Lilia Pitta, Cássio Machado e Humberto Tavares.

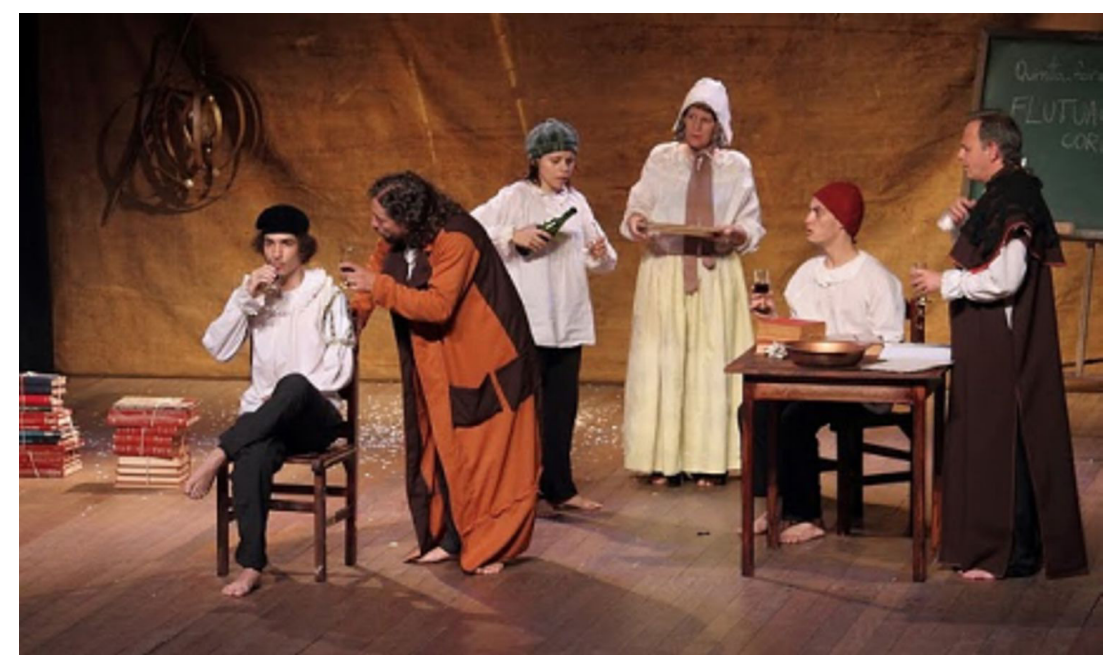

Fonte: Thomaz Harrel (2017).

No Brasil, a relação Arte e Ciência - em se tratando de produção da espetacularidade - realça, quase sempre, a histórica montagem da peça Galileu Galilei, de Bertolt Brecht, encenada por José Celso Martinez Corrêa em 1968. E, por ter sido montada em um contexto de ditadura 
e de perseguição política, a montagem do grupo Oficina deixou marcas a respeito da relação entre Ciência e Teatro, em um contexto em que se valorizava a inovação como uma forma de resistência política. Este texto de Brecht só veio a ter nova montagem de impacto em 1998, com a encenação da diretora Cibele Forjaz.

Foi também uma importante referência à montagem internacional que o Piccolo Teatro de Milão realizou de A Vida de Galileu, em 1962, que, sob a direção de Giorgio Strehler, impactou a cena mundial no século XX, tamanha foi a força do elenco e a visualidade cênica que alcançaram a partir da concepção cenográfica construída por Luciano Damiani. Portanto, as referências de montagens anteriores aprofundavam o desafio que tínhamos pela frente.

Frente a isso, ainda era possível notar que a peça de Brecht continuava sendo um importante parâmetro, um exemplo de discussão do papel da Ciência, principalmente acerca de sua função social. Há que se lembrar do que o personagem Galileu diz: "se as conquistas científicas não servirem para libertar o ser humano, elas não serviram para nada" (BRECHT, 2001).

No tocante à relação teatro e ciência no Brasil, não vêm de longa data as experiências de grupos teatrais com a questão dos temas científicos no palco. A década de 1990 trouxe um crescimento considerável de grupos teatrais brasileiros e grupos de teatro universitários. Há que se destacar, aqui, a presença do grupo Arte e Ciência no $\mathrm{Palco}^{4}$, da cidade de São Paulo, que consolidou seu repertório especializado em apresentações sobre Ciência nos últimos anos com as peças: Einstein, Copenhagen, Perdida e o espetáculo infantil Da Vinci, pintando o sete, dentre outras.

No meio universitário, percebemos que algumas experiências vinham se consolidando com relativo sucesso, como é o caso do Projeto Mensageiro das Estrelas, coordenado pelo Museu da Vida FIOCRUZ. O Grupo Ouroboros de divulgação científica UFSC, que além de montagens, também promove eventos sobre a relação Arte e Ciência. No mesmo caminho também mereceu destaque o Grupo Ciência Cênica da UNIVASF. Não esquecendo que esse movimento também tem atingido uma direção crescente no plano internacional, como é o caso de universidades portuguesas que também já consolidam importantes grupos e de montagens acerca da interação Arte e Ciência.
O grupo foi criado, em 1998, por Carlos Palma e Adriana Carui e, com a chegada de novos integrantes, em 2001, se consolidou junto a Cooperativa Paulista de Teatro. O núcleo Arte Ciência no Palco (ACP) dedica-se "ao fazer teatral pensando no homem e na sociedade com a lente da ciência" Assim, investigar a relação da arte e da ciência é seu objetivo. Por meio do teatro, com sua imensa capacidade de envolver, emocionar e provocar, ACP procura apresentar pelo "sentir" e pelo "pensar" os conflitos éticos da ciência. Além de entreter, despertar o público para as responsabilidades e consequências dos avanços da ciência pode ser uma consequência muito produtiva. (http://www.arteciencianopalco.

com.br/mais.html). 
Em nossa própria universidade, aqui na Universidade Federal de Uberlândia, há o pioneiro trabalho de extensão do Museu Diversão com Ciência e Arte (Dica), coordenado pelo Instituto de Física, e que foi recentemente reconhecido pelos órgãos superiores em virtude de seu trabalho com crianças dentro e fora da universidade.

Todo este mapeamento permitiu identificar as imbricaçóes entre dois campos que lidam com a criação e a inovação no âmbito da universidade, mas que por questóes de espaço físico, departamentais e políticas têm se distanciado cada vez mais, ao ponto de as Ciências serem nomeadas como áreas das "ciências duras" e as artes como áreas sem aplicaçôes "práticas" na vida. Ao apostar na extensão interdisciplinar, apoiados por um edital Fapemig, nosso projeto permitiu problematizar também a ideia de que atividades extensivas com Arte e Ciência só podem ser realizadas a partir das respectivas áreas.

Assim sendo, concordamos com Edgar Morin (2001), quando sublinha que o mundo contemporâneo, repleto de tecnologias, mas carente de sensibilidades, precisa de uma "religação", de religar pensamentos, saberes e ideias das pessoas, para com isso poder explorar o campo das possibilidades e oportunidades, que poderão ser concretizadas em "projetos e açôes numa cultura de paz" (MORIN, 2001, p. 27).

O texto de Brecht levou nosso grupo de atores a muitas reflexóes e, a cada dia, todos foram entrando em seu mundo próprio e no universo do renomado cientista Galileu Galilei. Todos sabiam que a peça não era exatamente uma obra de biografia, mas havia ali muita informação real e, por isso, o elenco se debruçava sobre elas, entravam a cada dia nesse mundo e descobriam as contradiçóes que eram apresentadas. Descobrindo Brecht, descobrindo Galileu e descobrindo a si próprios, em uma relação com a ciência, com o futuro público espectador, com a arte e com o ofício da atuação. Uma tessitura que ligava os pontos, entre a vida do cientista e a vida de artista de teatro. Assim, todos se investigavam a cada momento, próximo ao que nos lembra o diretor Peter Brook (2002, p. 26):

O Teatro talvez seja uma das artes mais difíceis porque requer três conexóes que devem coexistir em perfeita harmonia: os 
vínculos do ator com sua vida interior, com seus colegas e com seu público.

Leituras, releituras, aprofundamento, mais discussóes e, então, chega o momento de todos se levantarem da mesa de pesquisa e passar para o chão da sala de ensaio. Desse modo foram propostos exercícios que propiciavam descobrir as possibilidades corporais que aquele texto indicava, sentindo na pele, no tato, o que seria o Galileu de cada um, inerente ao presente histórico de todos.

A cada dia o grupo ia criando uma homogeneidade, uma cara, os corpos iam se alinhando, as propostas iam se alinhavando e o coletivo se superava, rompia e se destravava daquilo que estava acostumado, saindo de suas zonas de conforto em busca de uma experiência nova, um tempo novo e, ao mesmo tempo, maduro, consciente de onde se queria chegar.

Imagem 2: Cena de Galileu Galilei. Em cena os atorxs Valéria Gianechini e Narlo Santos.

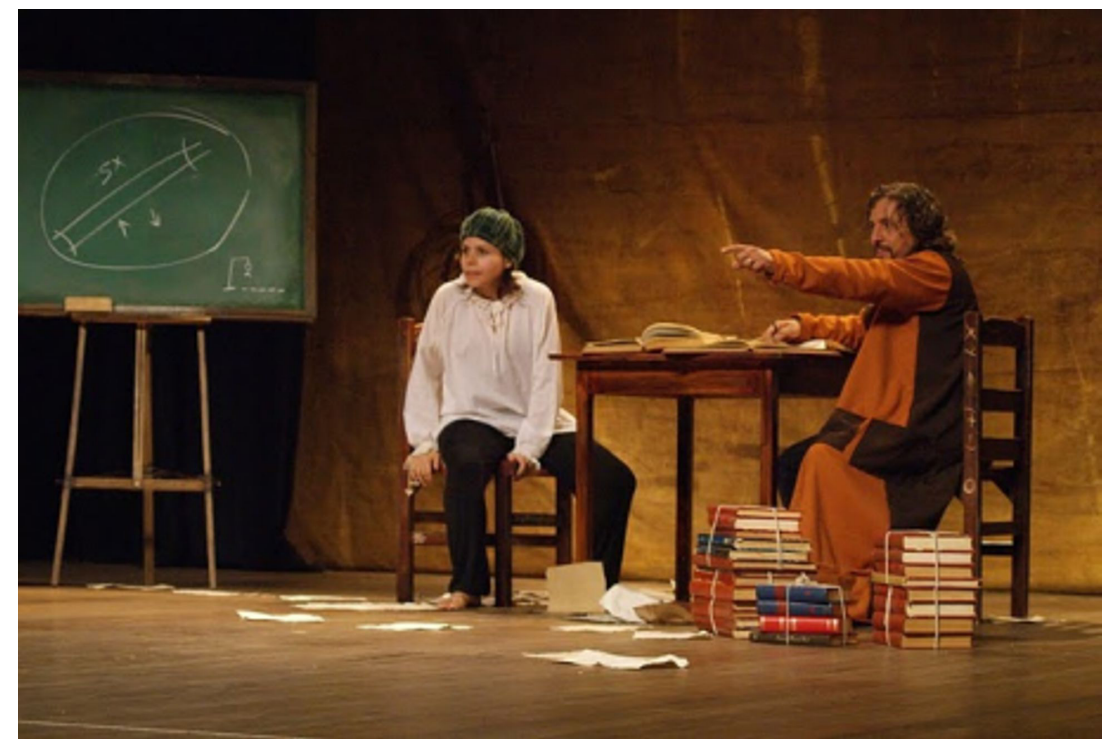

Fonte: Thomaz Harrel (2017).

Havia um forte desejo de não se repetir, havia uma busca pelo que ainda não se conhecia e uma vontade de superação em todos os sentidos. E foram muitas as superaçóes: corporais, pessoais, mentais, relacionais e, tudo isso, canalizado para uma força para continuar. 
Brecht era uma pedra preciosa, que seria lapidada a cada dia, e então, a cada dia ela mostraria sua forma e a cada dia mostraria sua beleza, seu brilho.

$\mathrm{Na}$ sequência, aliado ao trabalho com o texto e com a palavra de Brecht, iniciou-se o trabalho corporal ${ }^{5}$. Era necessário que o elenco desenvolvesse um corpo preparado, atento e disponível para as técnicas que o teatro brechtiano exigia. Procedimentos em que o ator conta uma história sem necessariamente lançar mão de psicologismos exagerados. Para isso, deveríamos abandonar cacoetes e qualquer "ruído" corporal, para que o corpo estivesse a favor da linguagem teatral que escolhemos. Assim, desenvolver uma unidade entre as qualidades dos atores participantes.

Nas primeiras semanas de treinamento corporal as dificuldades e limitaçôes vieram à tona inúmeras vezes. Eram comuns as dores no corpo até que o condicionamento fosse adquirido e assimilado. Aliado à preparação corporal, era comum discutirmos, antes de cada prática, a finalidade de cada exercício, um fragmento das teorias do teatro brechtiano ou uma frase sobre algum outro pensador ou homem de teatro que dialogasse com o nosso trabalho ou simplesmente inquietaçóes do grupo que, diga-se de passagem, eram muitas.

Além disso, foi importante a leitura da obra Galileu anticristo, uma biografia, de Michael White (2009). A partir desta escolha, cada ator era responsável por um ou mais capítulos que eram lidos e discutidos a cada encontro, extraindo e compartilhando a vida e o tempo de Galileu, seu pensamento sobre ciência, os avanços propostos e os históricos embates com as concepções da Escolástica Católica.

Nesse ínterim, foi muito importante a visita à casa do Professor Roberto Silvestre, astrônomo amador, dono do Observatório Astronômico de Uberlândia ${ }^{6}$, construído por iniciativa particular em sua própria residência e muito utilizado para a divulgação da Astronomia. Nele, pudemos conferir um céu límpido - talvez o mesmo visto por Galileu - além de Júpiter e suas luas, o que gerou inúmeras curiosidades a respeito do mundo das estrelas e do vasto universo que habitamos. Foi uma surpresa ver Júpiter e suas luas, uma imagem que ficará guardada para sempre em nossas mentes, pois, além de inédita para todos, ela também era parte importante de uma das cenas mais envolventes do espetáculo, que é quando Galileu
5 Conduzido pela diretora de cena Yaska Antunes e pelo assistente de direção Cássio Machado.

${ }^{6} \mathrm{O}$ observatório é equipado com um telescópio refletor newtoniano, de montagem equatorial robusta, construído por Leonel Vianello, de Araraquara/SP. Possui um espelho parabólico de $275 \mathrm{~mm}$ de diâmetro, com $1650 \mathrm{~mm}$ de distância focal e dispóe de um pequeno motor para anular o efeito causado pela rotação da Terra, possibilitando o acompanhamento automático dos objetos celestes. 
Galilei observa com seu amigo Sagredo, pela primeira vez, as luas de Júpiter e, naquele momento, na visita ao observatório, nós pudemos sentir um pouco daquilo que foi a sensação desses personagens ao ver o inédito planeta.

Essa observação nos levou a refletir sobre várias coisas a respeito do espetáculo e da vida dos personagens, pois acessar um telescópio no mundo contemporâneo foi, de certa forma, fácil. Mas imaginem naqueles tempos - século XVI - em que o alcance do instrumento produzido por Galileu náo tinha mais do que 5 ou 7 vezes de ampliaçáo, tendo ele, ainda, defendido a teoria de que Júpiter tinha luas que giravam à sua volta.

Aos poucos o elenco foi sentindo necessidade do "corpo de pé" e disposto para a improvisaçáo. Iniciou-se pela primeira cena, a qual todos deveriam fazer, deveriam passar pelos personagens Galileu e Andrea. O jovem Andrea era filho da empregada, convivia diretamente com Galileu e, por esse motivo e pela afinidade entre ambos, tornarase seu aprendiz. Aos poucos, a curiosidade infantil encontra seu lugar nas inquietaçôes científicas descritas por Galileu.

A definição dos personagens foi um momento especial, no qual cada ator começaria a colocar em prática, na cena, tudo aquilo que tinha experimentado até entáo. E esse foi mais um momento de rompimento de limites, pois Brecht apresentava muito mais personagens do que se tinha de atores disponíveis. $\mathrm{O}$ resultado foi que, com exceção do Galileu, um mesmo ator interpretaria vários personagens.

Com os personagens definidos iniciaram-se as leituras dirigidas, em que cada ator agora leria seu papel e poderia, entáo, fazer suas propostas de intençóes do texto. Momento este de se ganhar mais segurança e ir descobrindo um pouco mais o que seria o personagem de cada um.

Foram nove meses seguidos, com ensaios de no mínimo quatro dias por semana até nossa estreia. A montagem das cenas começou, então, com a atitude de levar para o palco tudo aquilo que tinha sido pesquisado, sentido, visualizado, ouvido, experimentado. Assim, as cenas foram tomando corpo e os atores foram se ajustando aos papéis.

Um longo processo, no qual cada dia começava com um aquecimento 
corporal e vocal, com exercícios que despertariam os corpos e mentes para o trabalho que se seguiria. Após o aquecimento, escolhia-se a montagem de uma cena específica, em que todos colocavam suas mentes e corpos para funcionar. Para esse momento foi muito importante o acesso a tudo o que se tinha aprendido até então: técnicas teatrais, estudos históricos sobre teatro - principalmente sobre o teatro épico - estudos políticos, biografias dos personagens, filmes e tudo aquilo que fora primordial para o enriquecimento processo de criação.

Deparávamo-nos, a todo instante, com a complexidade do texto de Brecht, que nos exigia incansáveis discussóes a respeito dos subtextos. Havia muitas inquietaçóes a respeito do Galileu apreendido da biografia e o personagem Galileu de Brecht, ambos construções da escrita, mas claro que a biografia apresentava mais elementos do homem, do cientista que realmente viveu a Renascença. No entanto, os diálogos compostos pelo dramaturgo alemão apontavam para a necessidade de entender Galileu como ser humano, cheio de curiosidade, de sonhos, de ambiçôes, mas também de fragilidades, capaz de duvidar e recuar de suas certezas. Essa visão foi bastante debatida com a visita do diretor paulista Sérgio de Carvalho $^{7}$, que muito nos ajudou neste entendimento do personagem brechtiano, dramaturgo que viveu o intenso século XX, num período de guerra.

A peça $A$ Vida de Galileu é considerada por alguns autores um texto teatral diferenciado, que foge um pouco da linha brechtiana, pois é, ainda hoje, um texto clássico, no qual a palavra possui grande importância. Por esse motivo, o contexto de nossa montagem exigia dos atores um domínio singular de cada frase e palavra.
Sérgio de Carvalho é dramaturgo, diretor e fundador da Companhia do Latão, grupo teatral de São Paulo. É professor de Dramaturgia e Crítica na Universidade de São Paulo, onde coordena o Laboratório de Investigação em Teatro e Sociedade (LITS) da Escola de Comunicaçôes e Artes (http://www. sergiodecarvalho.com.br/). 
Imagem 3: Cena de Galileu Galilei. Em cena os atorxs: Humberto Tavares, Ana Flávia Felice, Cássio Machado, Breno Maia, Lilia Pitta e Valéria Gianechini.

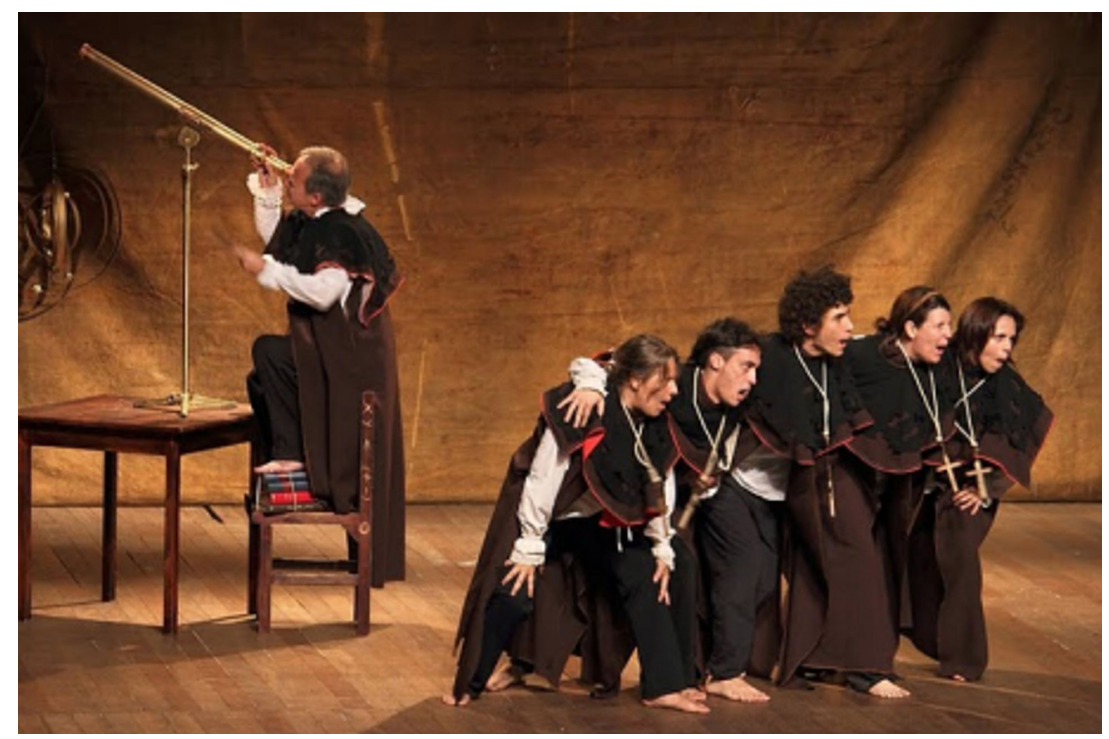

Fonte: Thomaz Harrel (2017).

Outro ponto importante nesta fase de nossa montagem foi a descoberta e criação dos objetos de cena. A partir do texto depreendiam-se apenas imagens daquilo que eram os objetos na época. Apareciam imagens do astrolábio, do telescópio, do sistema copernicano etc. Mas o que seriam os nossos objetos, como seriam, que material iríamos utilizar? $\mathrm{O}$ nosso desejo não era o de fazer réplicas perfeitas, mas sim fazer objetos que iriam ser úteis e funcionais para as cenas, objetos que teriam a "cara" de nosso espetáculo e que tinham também que compor com tudo aquilo que achávamos importante estar em cena.

Assim, ao longo de meses, fomos formando e moldando o nosso Galileu, e quando estávamos bem avançados no processo, fomos eliminando algumas coisas que não achávamos tão necessárias para o espetáculo, e uma delas foi uma parte do cenário que utilizávamos para ensaios, e isso nos trouxe uma renovaçáo, um frescor e uma convicção de não sermos apegados a nada que já esteja pronto. Daí então, pudemos reler algumas de nossas ideias e verificar se realmente aquilo funcionava, parafraseando o nosso personagem Galileu, quando diz: "o meu propósito não é provar que eu tenho a razão, mas de verificar se tenho". 
Assim, com este propósito nós também agimos, e muitas coisas que estavam fixadas em nossa montagem nós também começamos a verificar se seriam mesmo necessárias. E o mais interessante disso é que fizemos isso de maneira natural, em um processo científico que já estava enraizado no grupo e que foi crescendo ao logo da montagem.

Esse foi um processo realmente científico, que nos deu um grande prazer e, durante toda a nossa pesquisa, o que mais acontecia era nos maravilharmos com o que tínhamos descoberto, com o nosso material de pesquisa, com aquilo que tínhamos aprendido juntos e com tudo aquilo que ainda iríamos aprender.

O processo de uma montagem teatral não é feito só de descobertas e alegrias, mas também de angústias, de dores físicas e emocionais. Notavam-se, em todo o elenco, ao dar vida a seus personagens, pessoas sendo colocadas à prova, testadas nas suas crenças e sendo lançadas em lugares incomuns na busca pelo ato criativo. Assim, aos poucos, todos iam sendo motivados a serem garimpeiros, instigados a garimpar muito até acharem uma pedra semipreciosa e, na melhor das hipóteses, um diamante. $\mathrm{O}$ teatro sempre será uma arte essencialmente artesanal, feita de muito estudo, ensaios exaustivos e superação das limitações.

Ao fim, veio o que reforçou o caráter extensivo de nosso projeto, que foram as apresentaçóes teatrais que aconteceram na cidade de Uberlândia e Uberaba, aproveitando oportunidades como semanas acadêmicas de cursos de Artes, Teatro e Filosofia. Houve, assim, sempre que possível, uma preocupação com o registro e memória do projeto, com a realização de filmagens e promoção de debates com estudantes e professores nos locais do espetáculo.

Com a montagem de Galileu Galilei estabeleceu-se um espaço propício à investigação acerca da relação entre Arte e Ciência, sempre ancorados num texto clássico da dramaturgia mundial, $A$ Vida de Galileu, de Bertolt Brecht. A partir de um ambiente de inventividade instaurada fomentou-se a criação de uma peça teatral que circulou pela cidade de Uberlândia e região, levando às pessoas - na maioria jovens universitários - os dilemas vividos por um homem que queria pensar/produzir Ciência numa época tão difícil como foi o fim da idade média.

O impacto foi muito positivo, sublinhou-se a importância dos 
laços entre pesquisa e extensão e estabeleceu-se um diálogo e uma aproximação entre alunos da graduação, egressos e comunidade. Além disso, o projeto agregou alunos de diversas áreas do conhecimento. Proximidade essa que dificilmente se realiza na rotina normal do dia a dia universitário. Apresentando a Ciência e a Arte como áreas aparentemente diferentes, mas que possuem métodos e processos que lidam com a questấo da criatividade e com a inovação, questáo sine qua non para a formação de qualquer pesquisador. Um processo instigante, no qual compreendemos o longo caminho entre a poeira cósmica e os pés descalços no pó da sala de ensaio.

\section{REFERÊNCIAS}

BRECHT, B. Teatro completo. v. 6. Rio de Janeiro: Paz e Terra, 2001.

BROOK, P. A porta aberta. Rio de Janeiro: Civilização Brasileira, 2002. 103 p.

CELSO NETO, D. A. Bertolt Brecht na cena teatral brasileira: o redirecionamento do teatro no Brasil para uma visão engajada, moderna e inquietante: teoria e prática. In: SEMANA DE LETRAS "AS LETRAS E O SEU ENSINO", 9., 2006, Ouro Preto. Anais... Disponível em: https://pt.scribd.com/document/140241421/AsLetras-e-o-Seu-Ensino-Anais-Ix-Semana-de-letras-Livro. Acesso em: 20 nov. 2017.

MORIN, E. A religaçáo dos saberes: o desafio do século XXI. Rio de Janeiro: Bertrand Brasil, 2001. 588 p.

PALMA, C. O teatro da ciência. In: Revista Galileu. Edição 186. São Paulo: Globo, 2007. Disponível em: <http://revistagalileu.globo. com/Galileu/0,6993,ECT638589-3030,00.html>. Acesso em: 20 nov. 2017.

WHITE, M. Galileu anticristo: uma biografia. Rio de Janeiro: Record, 2009. 336 p. 